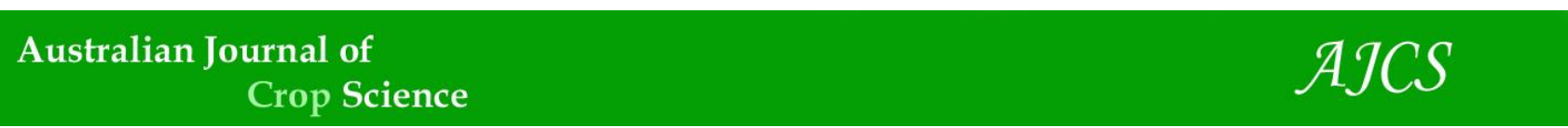

AJCS 12(02):318-325 (2018)

ISSN:1835-2707

doi: 10.21475/ajcs.18.12.02.p7685

\title{
Influence of the quality of artificial light on grafting tomato
}

\author{
Eva María Almansa ${ }^{1}$, Rosa María Chica ${ }^{2}$, María Teresa Lao ${ }^{1^{*}}$ \\ ${ }^{1}$ Department of Agronomy and Department of Engineering, Higher Polytechnic School, University of Almeria, Spain \\ ${ }^{2}$ Agrifood Campus of International Excellence CeiA3. Ctra. Sacramento s/n. La Cañada de San Urbano 04120 \\ Almería, Spain
}

\section{*Corresponding author: mtlao@ual.es}

\begin{abstract}
To improve the success of grafted tomato plants, the response under different types of lighting has been evaluated. The lights used are compact fluorescent, high efficiency fluorescent, standard fluorescent and pure Blue-Light-Emitting Diodes. The assay was conducted in a culture chamber under the following conditions: temperature (night-day) 17.5/19.8 $\circ \mathrm{C}(0.8 \pm 0.2 / 0.1 \stackrel{\circ}{\circ})$, relative humidity $56.44 / 72.40 \%\left(6.65 \pm 0.01 \%\right.$ ) and radiation 92,70 , and $36 \mathrm{Wm}^{-2}$. The tomato (Solanum lycopersicum L.) grafting method used was tube grafting with a small grafting clip using the cultivars Myla as scion and Maxifort as rootstock. Spectral radiation was measured at canopy level. Fresh and dry biomass in partitioning organs (leaves, stems and roots), Indol Acetic Acid (IAA), proline and reducing sugars were quantified. Standard fluorescent lamps have a very interesting spectral quality for grafting applications due to their B:R (blue:red), B:FR (blue:far red), PAR:NIR (Photosynthetically Active Radiation:Near Infrared) and R:FR (Red:Far Red)

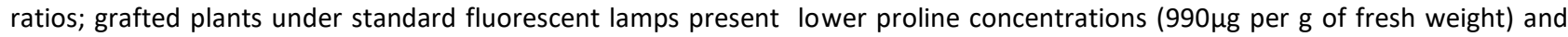
higher sugar concentrations ( $27 \mu \mathrm{g}$ per $\mathrm{g}$ of fresh weight) than plants under other treatments. Furthermore, standard fluorescent lamps ensure the highest stem and root growth as well as an adequate water status.
\end{abstract}

Keywords: auxin; carbohydrates; fluorescent lamps; light emitting diodes; proline; Solanum lycopersicum L.

Abbreviations: B_blue light; CF_compact fluorescent lamp; DW_dry weight partition; FR_far red light; FW_fresh weight; G_green; IAA_indol acetic acid; LED_light emitting diodes; LFW_leaves fresh weight; LPSC_leaf proline synthesis capacity; NIR_near infrared radiation; PAR_photosynthetically active radiation; PPF_photosynthetic photon flux; R_red light; T_treatment; TDW_total dry weight; TFW_total fresh weight; TL5_tubular lamp with the diameter of the bulb in eighths of an inch 5/8"; TLD_tubular lamp don's bulb; UV_ultraviolet.

\section{Introduction}

Tomato grafting has many potential benefits such as resistance to soil-borne disease, a decrease in nematode damage, superior quality fruit, higher yields, and greater efficiency in water and nutrient use as well as increased tolerance to abiotic stressors (Rivard and Louws, 2008).

Grafting is the union of two pieces of living plant tissue (scion and rootstock). The main goal of employing these agricultural practices is to control soil borne pathogens (Crino et al., 2007). However, the importance of vegetable grafting includes higher crop performance (Colla et al., 2008), higher tolerance to abiotic stresses such as salinity, alkalinity, nutrient stress, drought and heavy metal contamination (Colla et al., 2010, 2011, 2012, 2013; Kumar et al., 2015a,b; Rouphael et al., 2008, 2010; Schwarz et al., 2010; Savvas et al., 2010) as well as improving fruit quality (Proietti et al., 2008; Rouphael et al., 2010).

Auxins are a family of plant hormones which induce new vascular tissue by promoting cell elongation, division and development. They can be synthesized in leaves and travel down by polar transport promoting plant growth (Overvoorde et al., 2010). Light is an environmental factor that greatly effects lateral Indole-3-Acetic Acid (IAA) transport, and thus distribution of auxins in the plant (Sassi et al., 2013). The grafting process is regulated by plant hormones such as auxin and cytokinin (Shanfa, 2001). In addition, auxin levels are related to radiation quality (Kurepin et al., 2007) and intensity (Kurepin et al., 2008).

During the grafting process, the shoot donor (the scion) supports high drought stress. Proline is an amino acid which acts as an osmotic agent, protecting the plant from dehydration. Proline is also involved in multiple roles regarding the plants' tolerance to stress, acting as a mediator of osmotic adjustment. Under stress, light intensity plays a role in the promotion of proline accumulation (Zadebagheri et al., 2014).

However, photosynthesis is not related to proline concentration (Arora and Saradhi, 2002). Carbohydrates are related to PAR (Photosynthetically Active Radiation), and they are the main known source of energy in plants. Their abundance can be considered a major criterion of cell division activity and region differentiation. The quantity of carbohydrates can be expected to greatly influence the healing of graft wounds. The percentage of "take" in grafting of macadamia was found to be related to the relative amount of carbohydrates in the scions (Fahmy, 1952). 
Carbohydrate synthesis and proline are related to dehydration and drought stress; both of them, along with auxin synthesis, are modified by light intensity and spectrum quality (Tofiño et al., 2007). For this reason, artificial light treatments are used to improve grafting success (Shuangxia et al., 2006). The hypothesis of this work is based on how the spectral quality of light modifies grafting quality, related to the physiological changes induced.

The aim of this work is to evaluate the quality of grafting in tomato plants (Solanum lycopersicum), based on total and organ partitioning biomass and water status under four treatments, using different lighting lamps: fluorescents and light-emitting diodes.

\section{Results}

The relevant values associated with radiation from the agricultural point of view in order to characterize the quality of light (Almansa et al., 2011) are given in Table 1.

The spectrums of different treatments are shown in Fig 1. It is interesting to note that CF (compact fluorescent lamps), TL5 (tubular lamps with a bulb diameter of $5 / 8$ of an inch) and TLD (tubular lamps with a Don bulb) present peaks at $436,544,612 \mathrm{~nm}$, but only B-LED presents a wide peak at $470 \mathrm{~nm}$. The lowest total radiation is given off by B-LED

The UV (ultraviolet) radiation that was measured can be considered in the UV-A (ultraviolet-A) (320-400 nm) range. CF and TL5 have similar characteristics in UV-A, B (blue), R (red), NIR (near infrared) and TOTAL light, with values higher than TLD and B-LED. TL5 shows the highest values in the R (Red) and FR (Far red) regions. PAR (Photosynthetically Active Radiation) values in TLD treatments seem to be very low compared to CF and TL5. The CF treatment lamps are more powerful than the TL5 lamps, CF and TL5 show similar values of total radiation received by the grafts as CF lamps do not have luminaires. The low radiation intensity measured in B-LED, in contrast to TLD, could be due to lamp distribution and polarized light emission.

Table 2 shows the ratios between different spectral radiation ranges. The LED-blue spectrum is limited between 400-500 nm. It has not been possible to estimate the PAR:NIR, B:R, B:FR and R:FR parameters .

The relationship between PAR and Total radiation shows values near to one, corresponding to high photosynthetic efficiency radiation for all treatments (Table 2). The highest PAR:NIR lamp ratio can be seen in TLD (27.94) and this permits the use of this kind of lamp without causing heat damage to the plant. This value is higher than solar radiation which presents a ratio of about one. B-LED does not emit in the NIR range and for this reason it does not dissipate energy as heat. The CF treatment shows the highest $B: R(0.90)$ ratio. In TLD, the B:FR and R:FR parameter values were superior to other treatments. The latter two ratios were related to phytochrome and cryptochrome responses.

Ultraviolet-B (UV-B) radiation can cause a reduction of stem length due to an oxidation mechanism of the phytohormones. These plant hormones cause changes in cell size, such as the IAA, which is likely to be degraded by UV-B (Mark and Tevini, 1996); however, this parameter has not been measured. UV-A and blue light ranges show higher values in the CF and TL5 treatments. According to Kimura et al. (2004), we can expect a positive induction of process tissue repair in grafting plants related to enzymatic photoreactivation conducted by photolyase, an enzyme sensitive to UV-A -and blue light. Furthermore, blue light (B) is related to photo-morphogenic aspects of plant growth and their development (Sundström, 2000). The TL5 treatment presents the highest values of intensity radiation of the $R$ and FR regions; both of which indicate the extent to which the observed responses are mediated by the phytochrome (Hall and Rao, 1999). PAR values superior to our artificial sources were found in the literature. Nevertheless, in in vitro Grape propagation,PPF (photosynthetic photon flux) was fixed at $10.94 \mathrm{~W} \mathrm{~m}^{-2}\left(50 \mu \mathrm{mol} \mathrm{m} \mathrm{m}^{-1}\right)$ for all lighting systems (Poudel et al., 2008); artificial light at $10 \mathrm{~W} \mathrm{~m}^{-2}$ PAR also improved lettuce growth and decreased the duration of the production cycle (Gaudreau et al., 1994); photosynthesis of tomato (Solanum lycopersicum Mill.) was nearly linear within the photon flux range of 0 to $50 \mu \mathrm{mol} \mathrm{m} \mathrm{s}^{-1}$ from LEDs (Tennessen et al., 1995). Similar PAR values are found under CF and TL5 treatments. Near Infrared Radiation (NIR) is a useful part of radiation related to heat and the greenhouse energy balance (Castilla, 2005).

Notwithstanding, in a culture chamber, NIR only results in plant over-heating and in possible tissue damage. Spectral ratio, such as R:FR, is related to phytochrome photoequilibrium, and the B-light receptor (cryptochromes) is also involved in the photo-regulation of plant development, either independently or in conjunction with the phytochrome (Poppe et al., 2001). A B:R ratio close to 1 may indicate activation of cryptochromes and phytochromes. For this reason, responses due to cryptochrome activations must be considered in CF. The B:R (0.51) value for TL5 indicates that the plants received a greater amount of red light energy than blue light. Consequently, different responses are expected in tomato plants in relation to other treatments (Demers et al., 1998). With regard to the B:FR relationship, it is expected that the highest value (TLD) induced greater activation of cryptochromes against phytochromes. The values of B:FR and R:FR may be related to stem elongation due to the plants' response to blue and FR light (Park et al., 2015).

\section{Grafting light response}

\section{Biomass evaluation}

Fresh and dry weights of grafting plants at the end of the trial were evaluated as shown in Fig 2 and 3. Total leaf and stem fresh weight (FW) do not show significant differences between treatments. The root shows less fresh weight in TLD.

Total dry weight (DW) does not show significant differences between treatments. Nevertheless, the leaf, stem and root present differences in dry weight between treatments. CF shows the lowest dry weight of leaves and TL5 presents the highest dry weight of stems and roots.

The water status evaluated as the FW/DW ratio, related to the irradiative component of transpiration, decreases gradually in the following order: root, stem and leaf, in grafting plants for all treatments (Fig 3). CF has the highest 
Table 1. Agronomic characterization of light quality $\left(\mathrm{W} \mathrm{m}^{-2}\right)$.

\begin{tabular}{lllll}
\hline Treatments & CF & TL5 & TLD & B-LED \\
\hline UV-A $(320-400 \mathrm{~nm})$ & 0.18 & 0.20 & 0.04 & 0.00 \\
B $(400-500 \mathrm{~nm})$ & 2.81 & 2.04 & 1.51 & 1.22 \\
R(600-700 nm) & 3.12 & 3.97 & 2.19 & 0.00 \\
FR(700-800 nm) & 0.30 & 0.36 & 0.14 & 0.00 \\
PAR $(400-700 \mathrm{~nm})$ & 10.06 & 9.94 & 5.88 & 1.28 \\
NIR $(700-1100 \mathrm{~nm})$ & 0.47 & 0.47 & 0.21 & 0.00 \\
TOTAL $(300-1000 \mathrm{~nm})$ & 10.68 & 10.57 & 6.12 & 1.28 \\
\hline
\end{tabular}

Radiation: UV-A (ultraviolet-A); B (Blue); R (Red); FR (Far red); PAR (Photosynthetically Active Radiation); NIR (Near Infrared). CF (compact fluorescent lamp); TL5 (Tubular Lamp with a bulb diameter of 5/8" of an inch); TLD (Standard Tubular Lamp with a Don bulb); B-LEDs (Blue Light Emitting Diodes).
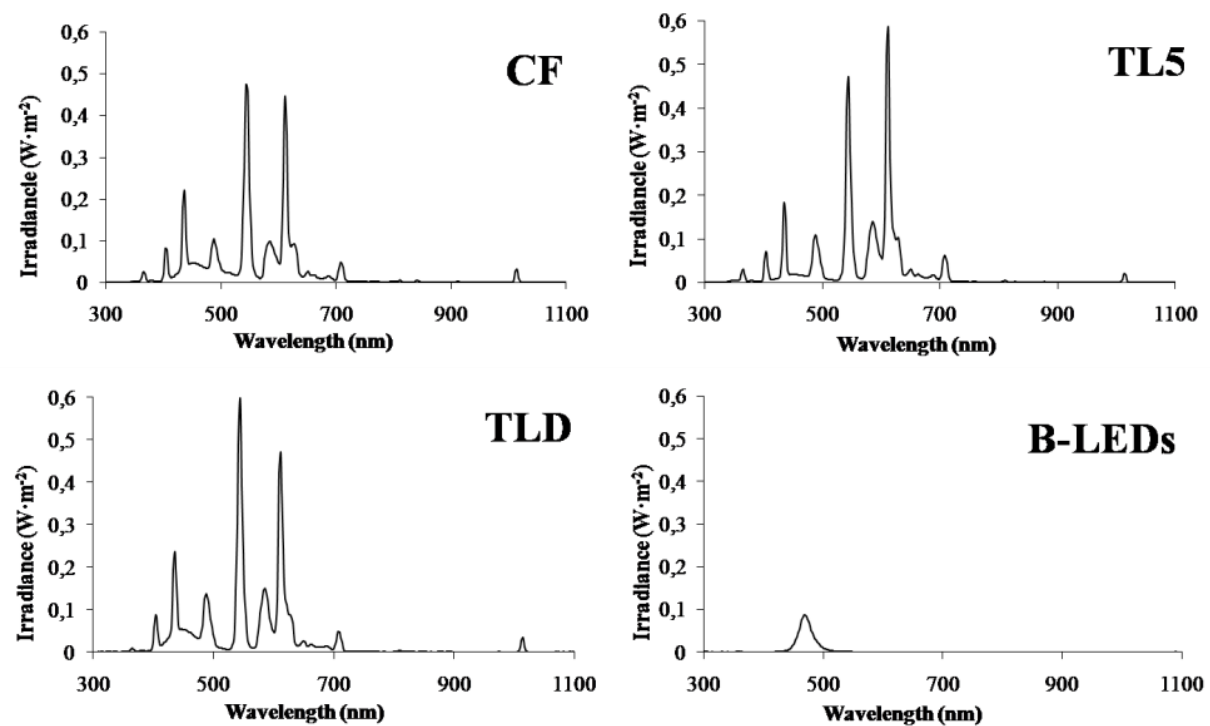

Fig 1. Spectral irradiance received by plants of different lighting treatments, measured at canopy level.

Table 2. Ratios between different spectral radiation ranges.

\begin{tabular}{lcccc}
\hline Spectral Fraction & CF & TL5 & TLD & B-LED \\
\hline PAR:TOTAL & 0.94 & 0.94 & 0.96 & 0.99 \\
PAR:NIR & 21.34 & 21.36 & 27.94 & \\
B:R & 0.90 & 0.51 & 0.69 & \\
B:FR & 9.30 & 5.70 & 11.00 & \\
R:FR & 10.34 & 11.13 & 15.89 &
\end{tabular}

Radiation: UV-A (ultraviolet-A); B (Blue); R (Red); FR (Far red); PAR (Photosynthetically Active Radiation); NIR (Near Infrared). CF (compact fluorescent lamp); TL5 (Tubular Lamp with a bulb diameter of 5/8" of an inch); TLD (Standard Tubular Lamp with a Don bulb); B-LEDs (Blue Light Emitting Diodes).

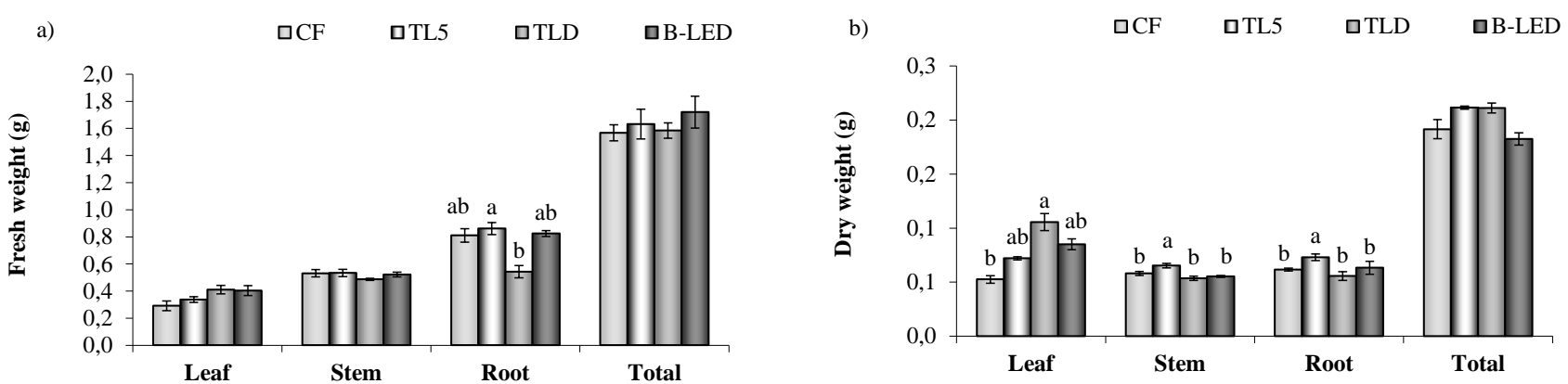

Fig 2. Total and organ partitioning biomass evaluated at the end of the trial on grafting plant a) Fresh and b) Dry weight. All mean s at the top of each column with the same letters are not significantly different at $p \leq 0.05$ by LSD test. 
Table 3. Lighting per treatments arranged by level. CF was positioned at the top and the others followed the established order.

\begin{tabular}{lll}
\hline Treatments & Lighting & \\
\hline CF & Compact fluorescent (CF) 23W (4 lamps) & \\
TL5 & High Efficiency Fluorescent TL5 35W (1 light MAXOS 4M691 x 2 lamps) \\
TLD & Fluorescent TLD 18W (1 light Philips TCS097 x 2 lamps) & 92 \\
B-LED & Pure Blue-Light-Emitting Diodes (B-LEDs) RGB & 36 \\
& (4 lines ALUM 40*25 LED SMD RGB $\times 9$ W with console DN-RGB FIBER LIGHT) & 36 \\
\hline
\end{tabular}

CF (compact fluorescent lamp); TL5 (Tubular Lamp with a bulb diameter of 5/8" of an inch); TLD (Standard Tubular Lamp with a Don bulb); TCS (Transmission Control System); B-LEDs (Blue Light Emitting Diodes); ALUM (aluminum); LED (Light Emitting Diode); SMD (Surface Mount Device); RGB (Red, Green and Blue colors); DN (Denon electronics brand).

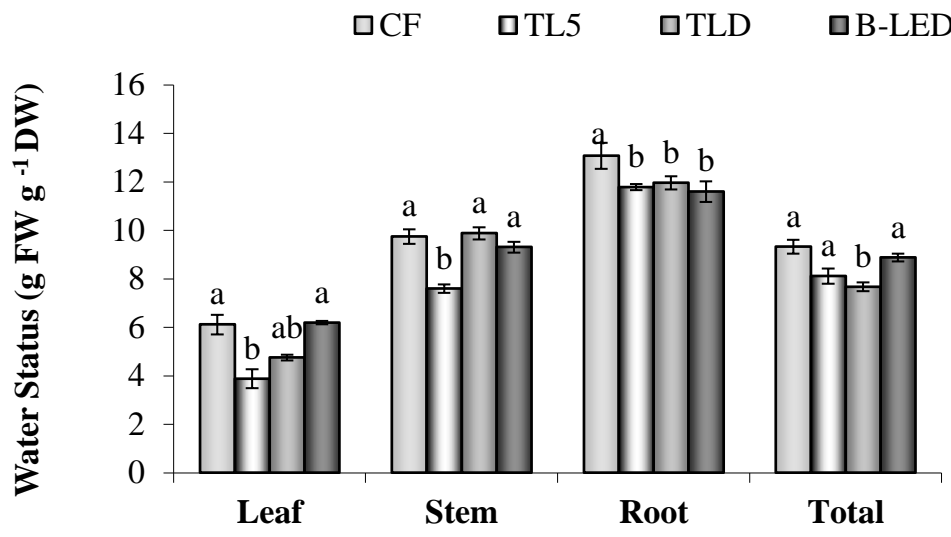

Fig 3. Water status and response to drought stress. Water status was established on fresh weight divided by dry weight (FW:DW ratio) for leaves, stems and roots. All means at the top of each column with the same letters are not significantly different at $p \leq 0.05$ by LSD test.

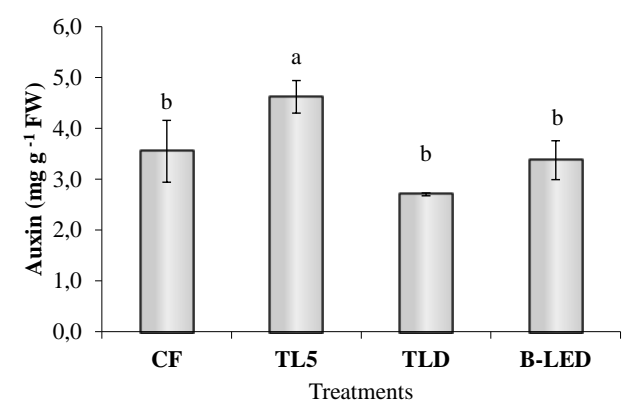

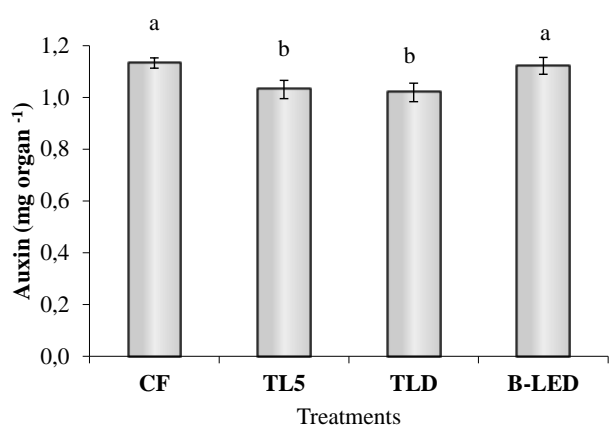

Fig 4. Auxins in grafting plant leaves. Total auxins were measured in supernatant fraction by colorimetry. All means at the top of each column with the same letters are not significantly different at $p \leq 0.05$ by LSD test.

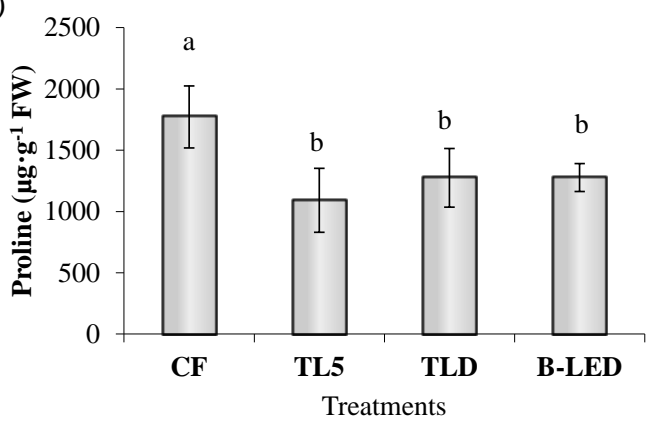

b)

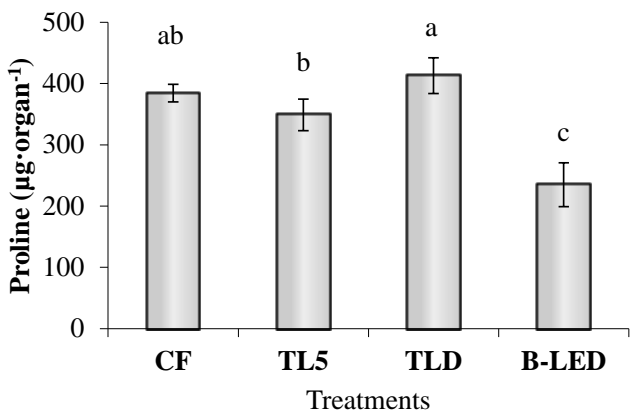

Fig 5. Proline grafting plant leaves. Total proline was measured in supernatant fraction by colorimetry. All means at the top of each column with the same letters are not significantly different at $p \leq 0.05$ by LSD test. 
a)

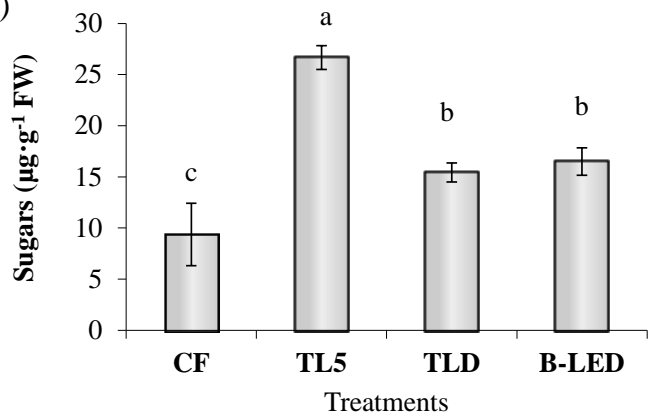

b)

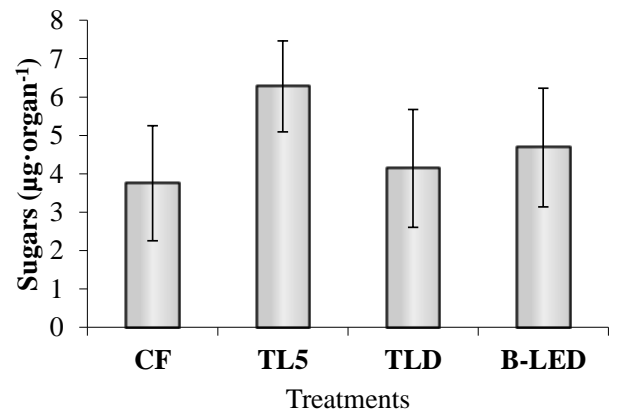

Fig 6. Reducing sugar concentrations in grafting plant leaves expressed in (a) micrograms of glucose by fresh weight, (b) micrograms of glucose by leaf. Total sugars were measured in supernatant fraction by colorimetry. All means at the top of each column with the same letters are not significantly different at $p \leq 0.05$ by LSD test.

FW/DW ratio of roots and TL5 has the lowest FW/DW ratio of leaves and stems. The values of stem and root DW in TL5 could be related to PAR, but the lowest value of leaf DW can be not related to PAR. Nevertheless, B-LED provided blue light to increase leaf growth and DW. Blue light inhibited shoot elongation, whereas leaf expansion was negatively affected only at the highest blue level (Rapparini et al., 1999). The TLD treatment provided the highest R:FR ratio related to phytochrome activation and its effects on total biomass accumulation and allocation (Humberto and Wulff, 2003). There are two spectral regions involved in the plant's water status defined by the FW/DW ratio: blue and NIR regions. Phototropins are activated by low blue radiation (Takemiyaa et al., 2005) and induced stomata opening (Briggs and Olney, 2001), with an increase in transpiration and water losses. On the other hand, when NIR increases, energy is converted into heat and, to maintain leaf temperature, water loss occurs through transpiration (Pieruschka et al., 2010). These reasons could explain the behaviour of TL5, but they do not explain the behaviour of CF. Nevertheless, a relationship between B:R and B:FR and auxin concentration may exist, as well as their joint auxin effect on cell turgor (Krieger, 1978).

\section{IAA and plant development}

The concentration and Leaf Auxin Synthesis Capacity (LASC), defined as auxin concentration in leaf ( $\left.\mu \mathrm{g} \mathrm{g}^{-1} \mathrm{LFW}\right)$ per Leaf Fresh Weight (LFW) (g) are shown in Fig 4 a) and b), respectively. The highest auxin concentration occurred in TL5, and similar values were found in the other treatments studied; however, LASC is higher in CF and B-LED than in TL5 and TLD. The lowest values of $B: R$ and $B: F R$ under TL5 treatment may be related to the increase in IAA production, and the fact that blue light stimulates their production. Kurepin et al. (2007) consider that a low R:FR ratio increases levels of endogenous IAA, but in this trial the R:FR ratio is similar in CF and TL5. The production of auxins by B-LED in aerial organs can be put down to cell differentiation (Horwitz, 1994) and growth of secondary roots (Günes, 2000 ) to ensure the survival of young plants (Geßner et al., 1999).

\section{Proline content in plant}

Proline concentration and Leaf Proline Synthesis Capacity (LPSC) are shown in Fig 5 a) and b), respectively. CF shows the significantly highest proline concentration. Similar values were found in the other treatments essayed. Nonetheless, LPSC is higher in CF and TLD than in TL5. B-LED presents the lowest value.

Proline is accumulated in plants during adaptation to environmental stresses (Claussen, 2005). Proline increased in the leaves of the plants when the time under water stress increased (Ismail et al., 1994). In our trial, the lowest FW/DW ratio occurred in TL5, but it does not show a high proline level. However, these values could be related to the highest sugar levels in TL5 as proline acts as an osmolite (Jang and Sheen, 1997). CF presents the highest proline concentration and this could be related to the highest total radiation received according to Zadebagheri et al. (2014). They considered that when light intensity increases, proline accumulation also increases. Relevant literature was found regarding the increase in proline content by UV radiation (Demir, 2000); Rajagopal and Madsen (1981) found unrolling of etiolated barley leaves, and reduction of the free proline under blue (426 nm) and red (658 $\mathrm{nm})$ light: However, leaf unrolling was prevented by FR $(728 \mathrm{~nm})$; light does not explain why total proline in leaves is higher in CF and TLD. Nevertheless, B:FR ratios could explain our results.

\section{Sugars and plant growth}

The concentration and total reducing sugar in leaves are given in Fig 6 a) and b), respectively. CF shows the significantly lowest value, TLD and B-LED provide intermediate values and TL5 presents the highest value. No differences have been found in total reducing glucose per leaf between treatments.

In short, photosynthesis is the highly efficient conversion of radiant energy into carbohydrates, and it consequently promotes growth (Alves de Alvarenga et al., 2003). Photosynthetically active radiation (PAR) contributes directly to photosynthesis and hence to crop growth. The lowest sugar content provided by the CF treatment may be related 
to the highest proline concentration and stress situation accompanied with a high respiration ratio. In terms of the production of sugar, the best treatment may be TL5. Nevertheless, the lowest leaf dry weight occurs in TL5. Kemp and Blacklow (1980) found an increasing over-supply of carbohydrates for growth of the shoot as the plant increased in size, related to the consumption of carbohydrates. TLD and B-LED demonstrate similar sugar concentrations and this could be related to the high dry weight of the stem and root in TLD, along with the consumption of carbohydrates in growth.

\section{Materials and methods}

\section{Plant material and growing conditions}

The tomato (Solanum lycopersicum) grafting methods used were tube grafting with a small grafting clip. A hundred grafts of tomato (cultivar 'Myla' as scion and 'Maxifort' as rootstock) were grown in expanded polystyrene seedling trays. Peat moss covered with vermiculite substrate was used. The plants were hand-watered daily with a Steiner nutrient solution (1961) (EC $1.5 \mathrm{dS} \mathrm{m}^{-1}, \mathrm{pH}$ 5.5). The density was 421 plants $\mathrm{m}^{-2}$. A Testo 625 Model 05636251 measured the air temperature and relative humidity inside the room.

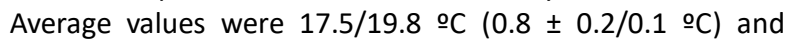
$56.44 / 72.40 \%$ (6.65 $\pm 0.01 \%)$ night-day for temperature and relative humidity, respectively. Similar conditions were found in commercial greenhouses for the second stage of development in the formation of a graft union (FernándezGarcía et al., 2004). This period was chosen because the major hydraulic connections within the graft union of tomato become functional over a period of about $48 \mathrm{~h}$ from the fifth day after grafting (Turquois and Malone, 1996).

\section{Plant sampling}

Experimental design consisted of 4 lighting treatments with 20 replications (one plant per replication), by treatments. Four days after grafting, plants were taken into the chamber. The trial lasted for five days, corresponding to the second stage of development in the formation of a graft union.

The experiment was conducted in a $1.8 \mathrm{~m}$ by $1.5 \mathrm{~m}$ culture chamber, equipped with different light treatments: compact fluorescents (CF), high efficiency fluorescent (TL5), standard fluorescent (TLD) and pure blue-light-emitting diodes (BLEDs). Table 3 shows the type of lamps and luminaires used in each treatment. Lamps were chosen taking into account the usual commercial equipment found in greenhouses (Chica et al., 2007) and simulation lighting models (Chica et al., 2008). Continuous lighting was applied following the recommendation of Black et al. (2003).

\section{Light measurements}

Spectral radiation was measured from $300 \mathrm{~nm}$ to $1100 \mathrm{~nm}$ in each shelf-treatment at canopy level with a Licor 1800 (LICOR inc. P.O. Box 4425 Lincoln, Nebraska 68504 USA).

\section{Plant analysis}

At the end of the trial, grafted plants were evaluated. Fresh and dry biomass partitioning between assimilation (leaves), conductive (stems and petioles) and absorption (roots) organs were measured using a precision balance (Mettler Toledo classic PB303-S; CH-8606 Greifensee, Switzerland).

Extraction was carried out by grinding fresh leaves with $95 \%+70 \%(1: 1 \mathrm{v} / \mathrm{v})$ ethanol. After filtering and centrifuging the samples at $5500 \mathrm{rpm}$ for $10 \mathrm{~min}$, IAA (Tien et al., 1979), proline, and sugars (Irigoyen et al., 1992) were quantified in supernatant fraction by colorimetry with a Spectrophotometer (Shimadzu UV-1201, Shimadzu; Kyota, Japan).

\section{Statistical analysis}

Analysis of data was carried out using software packages Excel 7.0 and Statgraphics (Stat- Point, Herndon, VA) plus 4.0. Analysis of variance and the Least Significant Difference (LSD) test for $p \leq 0.05$ were used to assess the significance of treatment means.

\section{Conclusion}

The use of standard fluorescent lamps (TLD) is the most successful treatment essayed as the grafted plants showed an adequate stem-root ratio and water status. TLD induced a lower proline level and a higher sugar level in grafted plants, corresponding with medium total radiation. TLD provided a lower PAR:NIR ratio (27.94) and a higher R:FR ratio (15.89). All these reasons lead us to the use of standard TLD type fluorescent lamps in post graft chambers in nurseries.

\section{References}

Almansa EM, Espín A, Chica RM, Lao MT (2011) Changes in endogenous auxin concentration in cultivars of tomato seedlings under Artificial Light. Hortscience. 46(5):698-704.

Alves de Alvarenga A, Mauro de Castro E, De Castro Lima Junior E, Magalhães MM (2003) Effects of different light levels on the initial growth and photosynthesis of Croton urucurana Baill. in southeastern Brazil. Rev Árvore. 27(1):53-57.

Arora S, Saradhi PP (2002) Light induced enhancement in proline levels under stress is regulated by nonphotosynthetic events. Biol Plantarum. 45(4):529-632.

Black LL, Wu DL, Wang JF, Kalb T, Abbass D, Chen JH (2003) Grafting tomatoes for production in the hot, wet season. AVRCD. 3(551): 1-8.

Briggs WR, Olney MA (2001) Photoreceptors in plant photomorphogenesis to date: Five phytochromes, two cryptochromes, one phototropin, and one superchrome. Plant Physiol. 125:85-88

Castilla N (2005) Plastic greenhouses, technology and management, Mundi-Prensa books, Madrid, Spain (in Spanish).

Claussen W (2005) Proline as a measure of stress in tomato plants. Plant Sci. 168:24-248. 
Chica RM, Almansa EM, Espín A, Lao MT, Jurado F (2007) Study on the use of additional artificial light in greenhouse production systems in the province of Almeria. Paper presented at the IV National Congress and I Iberian Congress of Agricultural Engineering, University of Albacete, Spain, 4-6 September 2007 (in Spanish, with abstract in English).

Chica RM, Almansa EM, Espín A, Lao MT, Jurado F (2008) Design a test to assess graft quality lighting tomato when applied to solar PV powered LEDs. Paper presented at the CIERTA 2nd international conference on renewable energy and water technology and water technologies, Roquetas de Mar, 2-3 October 2008 (in Spanish, with abstract in English).

Colla G, Rouphael Y, Cardarelli MT, Temperini O, Rea E, Salerno A, Pierandrei $F$ (2008) Influence of grafting on yield and fruit quality of pepper (Capsicum annuum L.) grown under greenhouse conditions Acta Horticulturae. 782: 359363.

Colla G, Cardona CM, Cardarelli MT, Rouphael Y (2010) Improving nitrogen use efficiency in melon by grafting. HortScience. 45(4): 559-565.

Colla G, Rouphael Y, Mirabelli C, Cardarelli MT (2011) Nitrogen-use efficiency traits of mini-watermelon in response to grafting and nitrogen-fertilization doses. J of Plant Nutri and Soil Sci. 174:933-941.

Colla G, Rouphael Y, Rea E, Cardarelli MT (2012) Grafting cucumber plants enhance tolerance to sodium chloride and sulfate salinizationSci Hortic. 135:177-185.

Colla G, Rouphael Y, Jawad R, Kumar P, Rea E, Cardarelli MT (2013) The effectiveness of grafting to improve $\mathrm{NaCl}$ and $\mathrm{CaCl}_{2}$ tolerance in cucumber. Sci Hort. 164: 380-391.

Crino P, Lo Bianco C, Rouphael Y, Colla G, Saccardo F, Paratore A (2007) Evaluation of rootstock resistance to Fusarium Wilt and gummy stem blight and effect on yield and quality of a grafted 'inodorus' melón. HortScience. 42(3): 521-525.

Demers DA, Dorais M, Wien HC, Gosselin A (1998) Effects of supplemental light duration on greenhouse tomato (Lycopersicon esculentum Mill) plants and fruit yields. Sci Hortic-Amsterdam. 74:295-306.

Demir Y (2000) Growth and Proline Content of Germinating Wheat Genotypes under Ultraviolet Light. Turk J Botany. 24:67-70.

Fahmy I (1952) Grafting studies on macadamia and sapodilla in relation to carbohydrates, using pre-girdled scions. FSHS. 190-192.

Fernández-García N, Carvajal M, Olmos E (2004) Graft union formation in tomato plants: peroxidase and catalase involvement. Ann Bot-London. 93(1):53-60.

Gaudreau L, Charbonneau J, Vezina L, Gosselin A (1994) Photoperiod and PPF influence growth and quality of greenhouse-grown lettuce. HortScience. 29:1285-1289.

Geßner M, Köhler HJ, Christoph N (1999) Atypical aging "in wine VIII. Vine and Wine (in Spanish).

Günes T (2000) Preoxidase and IAA oxidase activities during rooting in cuttings of three popular species. Turk J Botany. 24:97-101.

Hall D, Rao K (1999) Photosynthesis: Studies in Biology. Cambridge Univ. Press, UK.

Horwitz BA (1994) Properties and transducers chains of the UV and the blue light photoreceptors. In: Kendrick RE,
Kronenberg GHM (eds). 2nd ed. Photomorphogenesis in plants. Kluwer Acadenic Publishers, Netherlands, p 327350.

Humberto FC, Wulff RD (2003) Changes in the responses to light quality during ontogeny in Chenopodium album. Can J Bot. 81:152-163.

Irigoyen JJ, Emerich DW, Sánchez-Díaz M (1992) Water stress induced changes in concentrations of proline and total soluble sugars in nodulated alfalfa (Medicago sativa) plants. Physiol Plantarum. 84:55-60.

Ismail MR, Burrageb SW, Tarmizic H, Aziza MA (1994) Growth, plant water relations, photosynthesis rate and accumulation of proline in young carambola plants in relation to water stress. Sci Hortic-Amsterdam 60(12):101-114.

Jang JC, Sheen J (1997) Sugar sensing in higher plants. Trends Plant Sci. 2:208-214.

Kemp DR, Blacklow WM (1980) Diurnal extension rates of wheat leaves in relation to temperatures and carbohydrate concentrations of the extension zone. J Exp Bot. 31(3):821-828.

Kimura S, Tahira Y, Ishibashi T, Mori Y, Mori T, Hashimoto J, Sakaguchi K (2004) DNA repair in higher plants; photoreactivation is the major DNA repair pathway in nonproliferating cells while excision repair (nucleotide excision repair and base excision repair) is active in proliferating cells. Nucleic Acids Res. 32(9):2760-2767.

Krieger KG (1978) Early time course and specificity of auxin effects on turgor movement of the bean pulvinus. Planta 140(2):107-109.

Kumar P, Lucini L, Rouphael Y, Cardarelli MT, Kalunke RM, Colla G (2015a) Insight into the role of grafting and arbuscular mycorrhiza on cadmium stress tolerance in tomato. Frontiers in Plant Sci 6:477.

Kumar P, Rouphael Y, Cardarelli MT , Colla G (2015b) Effect of nickel and grafting combination on yield, fruit quality, antioxidative enzyme activities, lipid peroxidation, and mineral composition of tomato. J of Plant Nutri and Soil Sci. 178(6): 848-860.

Kurepin LV, Emery RJN, Pharis RP, Reid DM (2007) Uncoupling light quality from light irradiance effects in Helianthus annuus shoots: putative roles for plant hormones in leaf and internode growth. J Exp Bot. 58(8):2145-2157.

Kurepin LV, Emery RJN, Chinnappa CC, Reid DM (2008) Light irradiance differentially regulates endogenous levels of cytokinins and auxin in alpine and prairie genotypes of Stellaria longipes. Physiol Plantarum. 134(4):624-635.

Mark U, Tevini M (1996) Combination effects of UV-B radiation and temperature on sunflower (Helianthus annus L., cv Polstar) and maize (Zea mays L., cv. Zenit 2000) seedlings. J Plant Physiol. 148(1-2):49-56.

Overvoorde P, Fukaki H, Beeckman T (2010) Auxin control of root development. Cold Spring Harb Perspect Biol. 2010;2:a001537.

Park YG, Muneer S, Jeong BR (2015) Morphogenesis, flowering, and gene expression of Dendranthema grandiflorum in response to shift in light quality of night interruption. Int J Mol Sci. 16(7):16497-16513.

Pieruschka R, Huber G, Berry JA (2010) Control of transpiration by radiation. Proc Natl Acad Sci. 107(30):13372-13377. 
Poppe C, Sweere U, Drumm-Herrel H, Schäfer E (2001) The blue light receptor cryptochrome 1 can act independently of phytochrome A and B in Arabidopsis thaliana. The Plant J. 16(4):465-471.

Poudel PR, Kataoka I, Mochioka R (2008) Effect of red-and blue-light-emitting diodes on growth and morphogenesis of grapes. Plant Cell Tiss Org. 92(2):147-153.

Proietti P, Rouphael Y, Colla G, Cardarelli MT, De Agazio M, Zacchini M, Rea E, Moscatello S, Battistelli A (2008) Fruit quality of mini-watermelon as affected by grafting and irrigation regimes. J of the Sci of Food and Agri. 88: 11071114.

Rajagopal R, Madsen A (1981) Barley leaf unrolling. The proline connection. Physiol Plantarum. 51:7-12.

Rapparini F, Rotondi A, Baraldi R (1999) Blue light regulation of the growth of Prunus persica plants in a long term experiment: morphological and histological observations. Trees-Struct Funct. 14:169-176.

Rivard L, Louws J (2008) Grafting to manage soilborne diseases in heirloom tomato production. Hortscience. 43(7):2104-2111.

Rouphael Y, Cardarelli M, Rea E, Colla G (2008) Grafting of cucumber as a means to minimize copper toxicity. Environ. Exp. Bot. 63:49-58.

Rouphael Y, Schwarz D, Krumbein A, Colla G. (2010) Impact of grafting on product quality of fruit vegetables. Sci Hortic. 127: 172-179.

Savvas D, Colla G, Rouphael Y, Schwarz D (2010) Amelioration of heavy metal and nutrient stress in fruit vegetables by grafting. Sci Hortic. 127:156-161.

Schwarz D, Rouphael Y, Collac G, Venema JH (2010) Grafting as a tool to improve tolerance of vegetables to abiotic stresses: Thermal stress, water stress and organic pollutants. Sci Hort. 127:162-171.

Shanfa L (2001) The grafting of excised hypocotyl segment of plant in sterile culture. Acta Bot Yunnan. 23(1):91-96.
Shuangxia J, Shaoguang L, Xianlong Z, Yichun N, Xiaoping G (2006) An efficient grafting system for transgenic plant recovery in cotton (Gossypiumhirsutum L.) Plant Cell Tiss Org. 85:181-185

Sassi M, Wang J, Ruberti I, Vernoux T, Xu J (2013) Shedding light on auxin movement: Light-regulation of polar auxin transport in the photocontrol of plant development. Plant Signal Behav. 1;8(3):e23355.

Steiner A (1961) A universal method for preparing nutrient solution of a certain desired composition. Plant Soil. 15:134-154.

Sundström V (2000) Light in elementary biological reactions. Prog Quant Electron. 24:187-238.

Takemiyaa A, Inouea S, Doib M, Kinoshitaa T, Shimazakia K (2005) Phototropins promote plant growth in response to blue light in low light environments. The Plant Cell. 17:1120-1127.

Tennessen DJ, Bula RJ, Sharkey TD (1995) Efficiency of photosynthesis in continuous and pulsed light emitting diode irradiation. Photosynth Res. 44:261-269.

Tien TM, Gaskin MH, Hubbell DH (1979) Plant growth substance produced by Azospirillum brasilense and their effect on the growth of pearl millet (Pennistem americanun L.). Appl Environ Microb. 37: 219-226.

Tofiño A, Romero HM, Ceballos H (2007) Effect of abiotic stress on starch, synthesis and degradation. A review. Agron Colomb. 25(2):246-254.

Turquois N, Malone M (1996) Non-destructive assessment of developing hydraulic connections in the graft union of tomato. J Exp Bot. 47(5):701-707.

Zadebagheri M, Azarpanah A, Javanmardi S (2014) Proline metabolite transport an efficient approach in corn yield improvement as response to drought conditions. Intl J Farm \& Alli Sci. 3(5):453-461. 